Produto \& Produção, vol. 15 n.4 p. 01-16, dez. 2014

RECEBIDO EM 23/05/2014. ACEITO EM 09/11/2014.

\title{
Avaliação fatores chave implementação lean office
}

\author{
Daniella Martins Nunes \\ Universidade do Vale do Rio dos Sinos - UNISINOS \\ daninunes.eng@gmail.com
}

\section{Karla Faccio}

Universidade do Vale do Rio dos Sinos - UNISINOS

kfaccio@unisinos.br

\section{RESUMO}

O lean office adapta os conceitos e ferramentas do lean para as atividades e processos administrativos. A finalidade é a redução de custos, eliminar esforços desnecessários, aumentar a capacidade de resposta ao cliente e melhorar a rentabilidade global da empresa. O objetivo deste trabalho é avaliar cinco fatores chaves de sucesso para implementação do lean office, comparando as áreas fabril e não fabril em organizações que possuam lean implementado em algum nível. Para tanto, foi desenvolvido um survey, que foi postado no site LinkedIn, para profissionais das áreas de Melhoria Contínua e Lean. Foram obtidos 172 respostas válidas de diversos países. Os dados coletados mostram a importância dos cinco fatores para o sucesso do lean e as diferenças entre as áreas fabris e não fabris..

Palavras-chave: lean office, survey, fatores chave

\begin{abstract}
The lean office adapts the concepts and tools of lean to administrative processes. The purpose is cost reduction, eliminate unnecessary efforts, and improve customer responsiveness and the company global profitability. The objective of this paper is evaluate five key success factors to implement lean office, comparing the industrial e non industrial areas in companies which have lean implemented in some level. For that, was developed a survey, which was posted on LinkedIn, for Continuous Improvement and Lean professionals. The survey achieved 172 valid answers from many countries. The data collected highlights the importance of the five factors to lean success and the differences between industrial and non industrial areas.
\end{abstract}

Keywords: lean office, survey, key factors

\section{Introdução}

O comportamento do consumidor é influenciado pelo cenário político e econômico. Desta forma, as empresas devem adaptar seus processos e modelos de negócio para sobreviver às transformações do mercado. No contexto da gestão da produção, a indústria 
automotiva é inegavelmente a principal responsável pelas inovações. Iniciando com o sistema de Ford que, na década de 20, conduziu a fabricação artesanal de automóveis para a produção em massa. As décadas seguintes foram marcadas por um período de crescimento industrial acelerado. Sendo assim, uma época propícia para a produção em massa, dado que a demanda era maior que a oferta, com isso todos os produtos colocados à venda encontravam compradores. Assim, a produção em massa e o consumo em massa geravam ganhos de escala (ANTUNES, 2008).

A crise do petróleo, em 1973, gerou recessão e escassez de recursos em diversos países. Deste modo, houve uma alteração na relação entre a demanda e oferta e, a lógica de ganhos em escala tornou-se incompatível com este cenário. Neste contexto, o consumidor passa a ditar regras e a escolher entre modelos e fabricantes. Assim, nasce uma necessidade de flexibilização da produção que permitisse a fabricação de lotes menores e produtos diferenciados para atender ao novo perfil do consumidor (ANTUNES, 2008; WOMACK; JONES; ROOS, 2004).

Neste período de crise, a indústria japonesa Toyota manteve seu desenvolvimento, mesmo enquanto o Japão enfrentava taxas de crescimento próximo à zero. Este desempenho chamou atenção das demais indústrias. O sistema de produção desenvolvido pela Toyota tem foco na identificação e eliminação de desperdícios gerando a maximização do fluxo produtivo, tornando econômica a produção de um item de cada vez, sendo assim estratégia essencial ao novo mercado. O Sistema Toyota de Produção (STP) aparece como resposta à necessidade de flexibilização das indústrias. Em consequência, durante o período pós-crise, a Toyota tornou-se muito mais competitiva comparada às indústrias europeias e norteamericanas que mantinham seus sistemas de produção em massa inalterados (OHNO, 1997; WOMACK; JONES; ROOS, 2004). A publicação do livro The Machine That Changed the World, na década de 80, teve por objetivo disseminar os conceitos do STP no ocidente utilizando o termo Lean Manufacturing

Mais recentemente, a globalização e os avanços tecnológicos introduziram diferentes características ao mercado. Estas características ocasionam consumidores mais exigentes e com expectativas mais altas. As expectativas vão além do produto em si, consumidores passam a analisar a relação custo benefício e os serviços agregados ao produto, como prazos de entrega, pós venda e garantia (TENÓRIO, 2007).

Esse cenário exige das empresas inovações em outras áreas além do sistema de produção. As áreas ligadas diretamente ao cliente permitem agregar valor ao produto podendo influenciar na decisão de compra do consumidor. Ainda, as áreas administrativas e de apoio a gestão são essenciais para o funcionamento da empresa e representam grande parte dos custos operacionais. Segundo Tapping e Shuker $(2010$, p. 1), "é válido considerar que $60 \%$ a $80 \%$ de todos os custos envolvidos para satisfazer a demanda de um cliente [...] é uma função administrativa". Assim, verifica-se a necessidade de aumentar a eficácia destes processos e eliminar atividades que não agregam valor como forma de alcançar diferencial competitivo frente aos concorrentes (TAPPING; SHUKER, 2010).

$\mathrm{O}$ sucesso alcançado com o lean nas áreas produtivas pode ser repetido nas áreas $\mathrm{e}$ processos administrativos para promover melhorias através da identificação e eliminação de desperdícios. Uma vez que existem diferenças entre os processos do chão de fábrica e processos administrativos são necessárias adaptações ou simplificações dos conceitos para aplicação nos processos administrativos. Assim, o lean office utiliza os conceitos e ferramentas do lean adaptados aos processos administrativos.

O objetivo deste trabalho é avaliar cinco fatores chaves de sucesso para implementação do lean office, comparando estes fatores em organizações que possuem lean implementado em algum nível.

\section{Metodologia}

Para este estudo será realizado um survey do tipo exploratório com desenho interseccional com o objetivo de gerar conhecimento sobre o tema e sendo a coleta de dados em um único intervalo de tempo (BABBIE, 2003). 
O survey foi dividido em três seções de acordo com os objetivos específicos: dados demográficos, status da jornada lean, fatores chaves. Para a avaliação dos fatores chaves de sucesso as questões elaboradas comparam a posição das organizações em relação ao lean no chão de fábrica, áreas de apoio e áreas de suporte (Quadro 1).

Quadro 1 - Definição das áreas adotadas no survey

\begin{tabular}{|c|l|}
\hline (1) chão-de-fábrica: & $\begin{array}{l}\text { atividades de transformaçăo de matéria prima em } \\
\text { produto acabado e/ou para entrega do serviço ao } \\
\text { cliente; }\end{array}$ \\
\hline (2) áreas de apoio: & $\begin{array}{l}\text { envolvem as atividades primárias relacionadas ao } \\
\text { produto (vendas, logística interna, distribuição, projeto } \\
\text { e desenvolvimento, garantia, etc.); }\end{array}$ \\
\hline (3) áreas de suporte: & $\begin{array}{l}\text { envolvem as atividades de suporte a organização e a } \\
\text { produçăo (recursos humanos, financeiro, controladoria, } \\
\text { compras, gestão, etc.). }\end{array}$ \\
\hline
\end{tabular}

Fonte: Elaborado pela autora

A amostragem utilizada foi a não probabilística, uma vez que não é possível determinar o número exato de empresas que possuem o lean implementado. A sua utilização é conveniente quando toda a população não está disponível ou não é conhecida. Ainda, a amostragem não probabilística é menos dispendiosa, mais rápida e apesar das suas limitações apresenta contribuições nos estudos nos quais é empregada (MIGUEL, 2010; OLIVEIRA, 2001).

A pesquisa e seu objetivo foram divulgados pela rede social Linkedin em grupos relacionados aos seguintes assuntos: Melhoria Contínua, Lean, Lean Office, Engenharia de Produção e Qualidade. O survey recebeu 221 acessos, sendo 54 nacionais e 167 internacionais. Questionários incompletos foram excluídos da análise de dados.

Com o intuito de avaliar a fidedignidade do questionário, ou seja, verificar se o instrumento consegue medir ou inferir o que se propõe, utilizou-se o coeficiente Alfa de Cronbach. Considerou-se as 67 questões da terceira seção do questionário que tratam dos fatores chaves no sucesso da implementação do lean. O resultado encontrado foi $\alpha=0,971$, o que representa alta fidedignidade (FREITAS; RODRIGUES, 2005).

\section{Referencial teórico}

O lean pode ser definido como uma filosofia de gestão que busca entregar valor, pela perspectiva do cliente, otimizando a utilização de recursos. A estratégia é diminuir o lead time entre o pedido do cliente e a entrega, eliminando todos os desperdícios. Dessa forma, a empresa torna-se mais competitiva e a satisfação do cliente aumenta. (WOMACK; JONES, 1998).

A principal ideia é enxergar que o valor do cliente é criado pelas ações de muitas pessoas diferentes em muitos departamentos e organizações. Ligando esses processos em um único fluxo de valor para cada família de produtos aparecem muitas oportunidades para otimizar o fluxo, eliminando atividades que não criam valor e alinhando o fluxo com a demanda do cliente (WOMACK; JONES, 1998).

Os cinco princípios do lean orientam para identificar o valor pela perspectiva do cliente; mapear a cadeia de valor para o produto e fazer fluir continuamente todos os processos que criam valor, deixando que o cliente puxe o produto de acordo com a necessidade. Por fim, a busca da perfeição acontece na medida em que o sistema puxado evolui e, os obstáculos que impedem o fluxo contínuo aparecem e os desperdícios são eliminados, o produto ou serviço fica mais próximo da real necessidade do cliente (WOMACK; JONES, 1998).

Existem diversos casos de sucesso do lean em áreas industriais. No entanto, os processos administrativos são negligenciados e assim, não são percebidos os resultados e ganhos possíveis de serem alcançados nessas áreas (LOCHER, 2011). Os processos 
administrativos existem em todos os modelos e áreas de negócio mesmo assim, muitas empresas focam apenas na manufatura (GREEF et al., 2012). O próximo passo das empresas é considerar os processos não fabris que tem passado despercebidos (GONÇALVES, 2000).

McManus (2005) propõe reimaginar os princípios para adequar aos processos administrativos, que normalmente são processos intermediários e interdependentes e que devem ser mais eficientes apenas para facilitar o desempenho da operação fabril. O Quadro 2 apresenta diferenças na aplicação dos cinco princípios do lean na manufatura e nos processos administrativos.

\section{Quadro 2 - Aplicação dos princípios lean na Manufatura x Processos Administrativos}

\begin{tabular}{|c|c|c|}
\hline Princípios & Manufatura & Processos Administrativos \\
\hline Valor & $\begin{array}{l}\text { Visível em cada etapa, objetivos } \\
\text { definidos. }\end{array}$ & $\begin{array}{l}\text { Difícil de ser identificado, com objetivos } \\
\text { variáveis. }\end{array}$ \\
\hline $\begin{array}{l}\text { Fluxo de } \\
\text { valor }\end{array}$ & Materiais e partes & Informação e conhecimento \\
\hline Fluxo & Interações são desperdícios & Interações planejadas devem ser eficientes \\
\hline $\begin{array}{l}\text { Sistema } \\
\text { puxado }\end{array}$ & Guiadas pelo tempo takt & Guiadas pela necessidade da organização \\
\hline Perfeição & Repetição dos processos sem erros & $\begin{array}{l}\text { Processos possibilitam melhoria da } \\
\text { organização }\end{array}$ \\
\hline
\end{tabular}

Fonte: Adaptado de McManus (2005)

Em um processo administrativo as atividades estão relacionadas à "criação, captação, triagem, armazenamento, distribuição, uso e descarte de informação", correspondendo a um fluxo de informações (GONÇALVES, 2000; GREEF et al., 2012, p. 168). Um fluxo de informações falho gera dificuldades na conclusão das tarefas e desmotiva os funcionários acarretando em resultados negativos (TAPPING; SHUKER, 2010).

Nas áreas administrativas é comum encontrar processos desarticulados no qual as tarefas são individualizadas ocorrendo atrasos e problemas de comunicação. Ainda, existem processos com grande volume de atividades manuais, gerando alta intensidade de trabalho e necessidade de muitas pessoas. Além disso, sistemas de informação que são incompatíveis com o processo acarretam no uso do tempo para extrair informações e efetuar cálculos manuais. A interação entre as áreas ao longo do fluxo é difícil de ser transposta devido à visão de departamentos e funções. A alta variabilidade dos processos dificulta a padronização e decorrente estabilização do processo (GREEF et al., 2012; TAPPING; SHUKER, 2010; WOMACK; JONES, 1998). Estas características acarretam em inconsistências e má qualidade da informação necessitando de tempo extra para correções (LOCHER, 2011).

Do mesmo modo, por vezes as pessoas da área administrativa não estão familiarizadas com as técnicas e ferramentas para aumento de eficiência, comuns nas áreas fabris, uma vez que os processos administrativos raramente são analisados em busca de melhorias. As organizações tendem a fazer mudanças isoladas em departamentos ou funções, não enxergando o fluxo de trabalho e informações (LOCHER, 2011).

Em síntese, todos os itens apresentados mostram que a natureza do trabalho administrativo é diferente da manufatura principalmente porque possui etapas intangíveis que se traduzem em alta variação do processo e imprevisibilidade da demanda (LOCHER, 2011). O lean office é uma poderosa metodologia para melhorar processos administrativos ineficientes e "eliminar toda variação dos processos existentes em sua área administrativa" (GREEF et al, 2012; KEYTE; LOCHER, 2004; TAPPING; SHUKER, 2010). 
A adesão ao lean office aumenta a eficiência dos processos, identificando áreas com problemas e utilizando ferramentas adequadas para eliminar desperdícios, o que reduz custos com a otimização do trabalho e simplificação dos processos, além de gerar vantagem competitiva (CHEN; COX, 2012; GREEF et al, 2012; KEYTE; LOCHER, 2004; TAPPING; SHUKER, 2010).

A literatura apresenta diversos fatores inibidores do sucesso do lean nas organizações. Por exemplo, Scherer (2012) analisou 161 artigos que tratam da implementação do lean e identificou 14 fatores de risco ao sucesso na manufatura. Após, realizou uma análise bidimensional destes fatores de acordo com a abrangência e a natureza da atividade, apresentada no Quadro 3. É interessante perceber que 78,54\% (11 fatores) estão relacionados a atividades de suporte internas.

\section{Quadro 3 - Análise bidimensional dos fatores de risco quanto à abrangência e natureza da} atividade

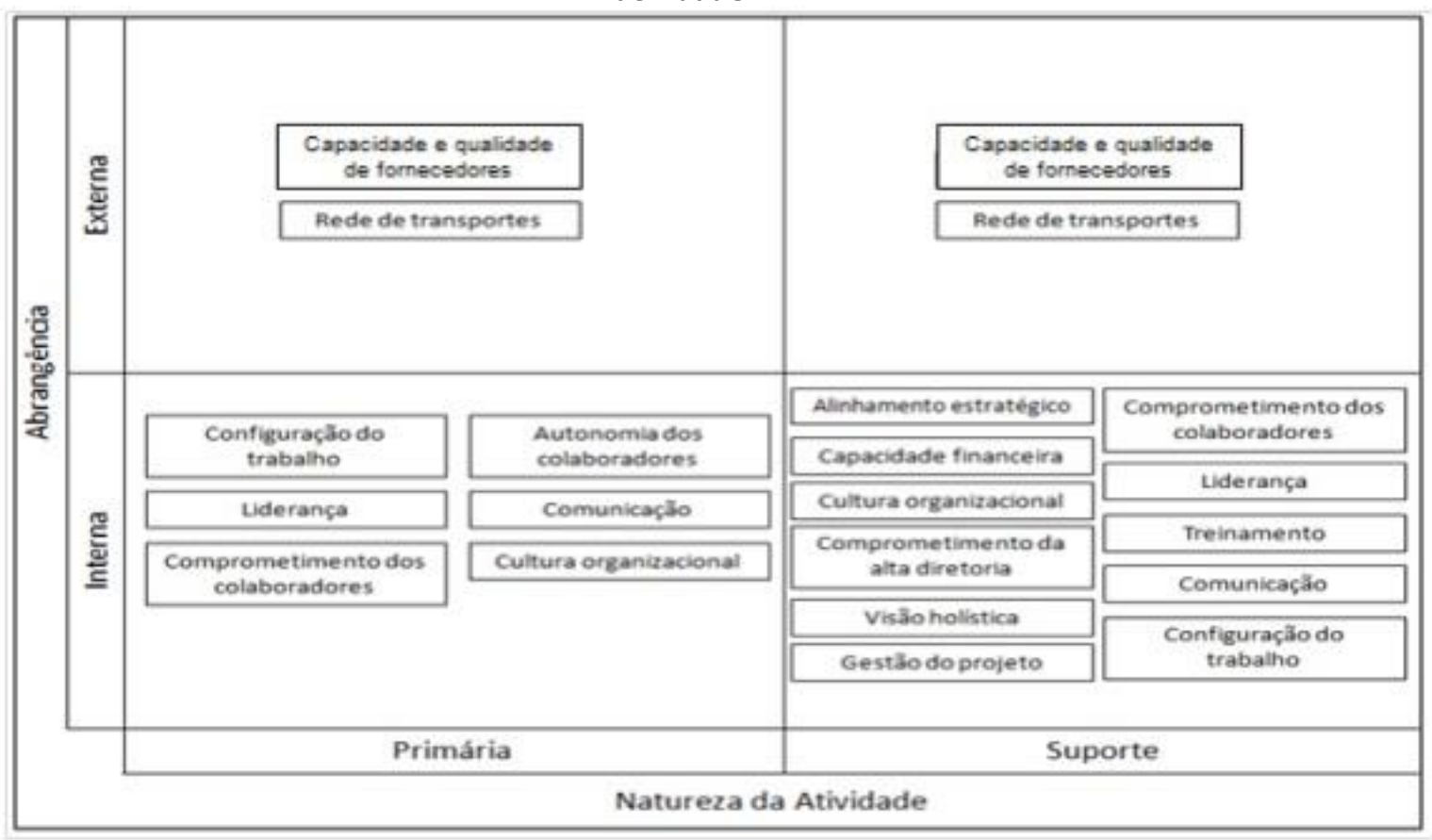

Fonte: Scherer (2012, p. 34)

As pesquisas de Saurin et al. (2010) e do Lean Enterprise Institute (MARCHWINSKI, 2007) incluem outros fatores de influência no insucesso na implementação do lean, como: dificuldade de quantificar os ganhos financeiros $(10,08 \%$ e $4,90 \%$ respectivamente), fracassos em tentativas passadas $(7,56 \%$ e $3,30 \%)$ e, a falta de recursos financeiros $(9,24 \%$ e $2,30 \%)$.

Serão considerados cinco fatores chave: liderança, treinamento e conhecimento, abordagem, cultura organizacional e pessoas. A escolha destes cinco fatores é decorrente do entendimento que os demais são consequência da falha destes.

\section{Resultados}

Os dados coletados com a aplicação do survey serão apresentados em grupos: nacional, internacional e geral, que contempla o somatório dos dois anteriores. A seguir, é apresentada a análise descritiva dos dados de cada seção do questionário. 
Os dados demográficos visam identificar características dos entrevistados com relação à área de atuação, porte da empresa e localização geográfica. Desta forma, das 172 respostas consideradas como válidas para este estudo, 41 respondentes estão localizados (Figura 1) no Brasil (nacional) e 131 respondentes estão localizados em diversas partes do mundo (internacional). A Figura 2 ilustra o número de funcionários das empresas.

Existe uma diversidade dos setores dos entrevistados que estão divididos em 36 áreas. Cinco setores representam 50\% do geral: 19,77\% aeroespacial, 11,05\% aeronáutica, 7,56\% agroalimentar, agroquímico e alimentício ambos com 5,81\%. Percebe-se que os princípios do lean podem ser aplicados a qualquer área e tipo de processo, conforme Womack e Jones (1998) afirmaram.

Figura 1 - Localização geográfica dos respondentes
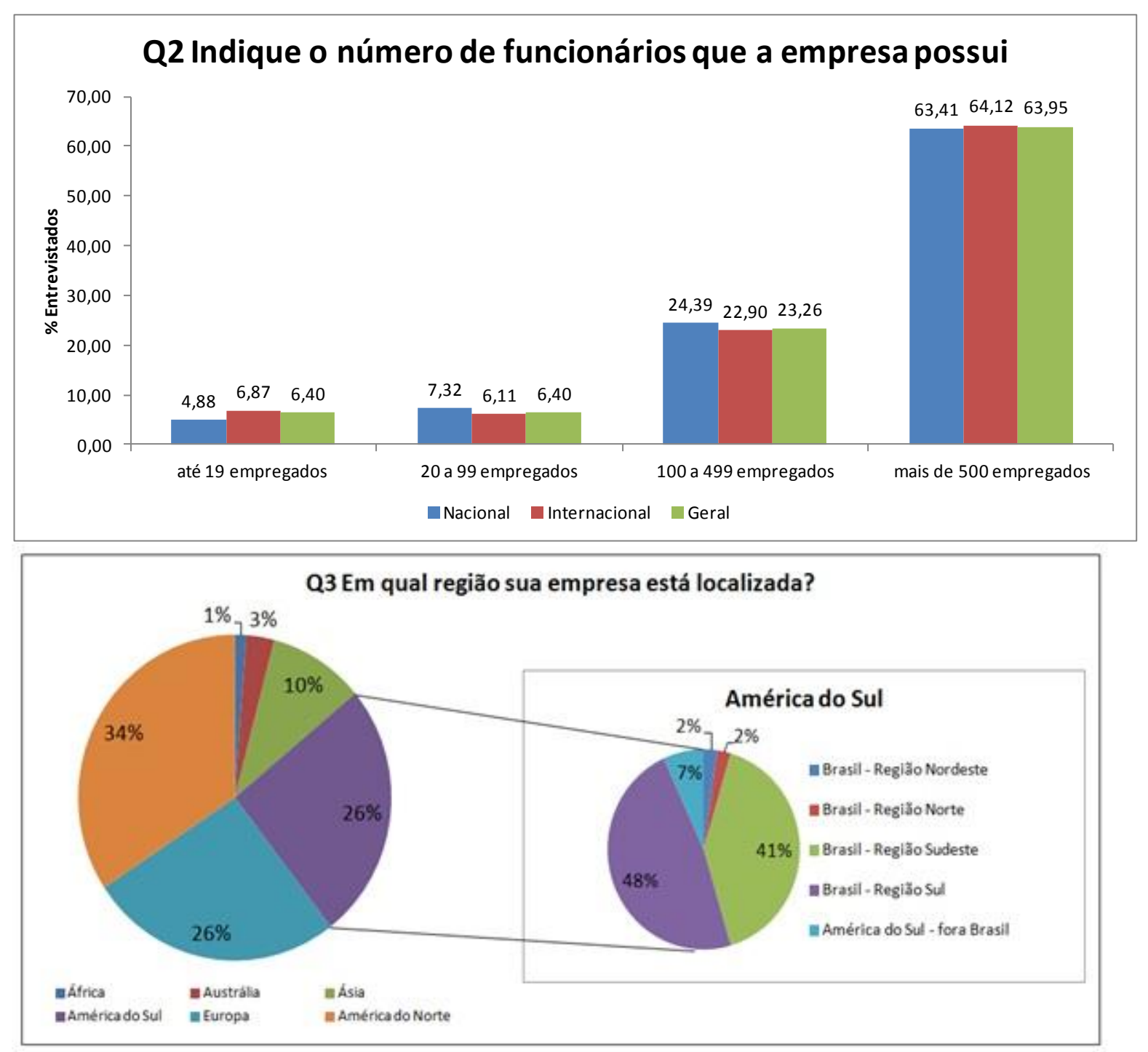

Fonte: Elaborado pela autora

Figura 2 - Número de funcionários na empresa do entrevistado

Fonte: Elaborado pela autora 
A questão que identifica há quanto tempo a organização está na jornada lean (Figura 3) foi considerada eliminatória e com isso, a resposta "Não iniciou a jornada" foram excluídas da análise.

\section{Figura 3 - Tempo que a organização do entrevistado está na jornada lean}

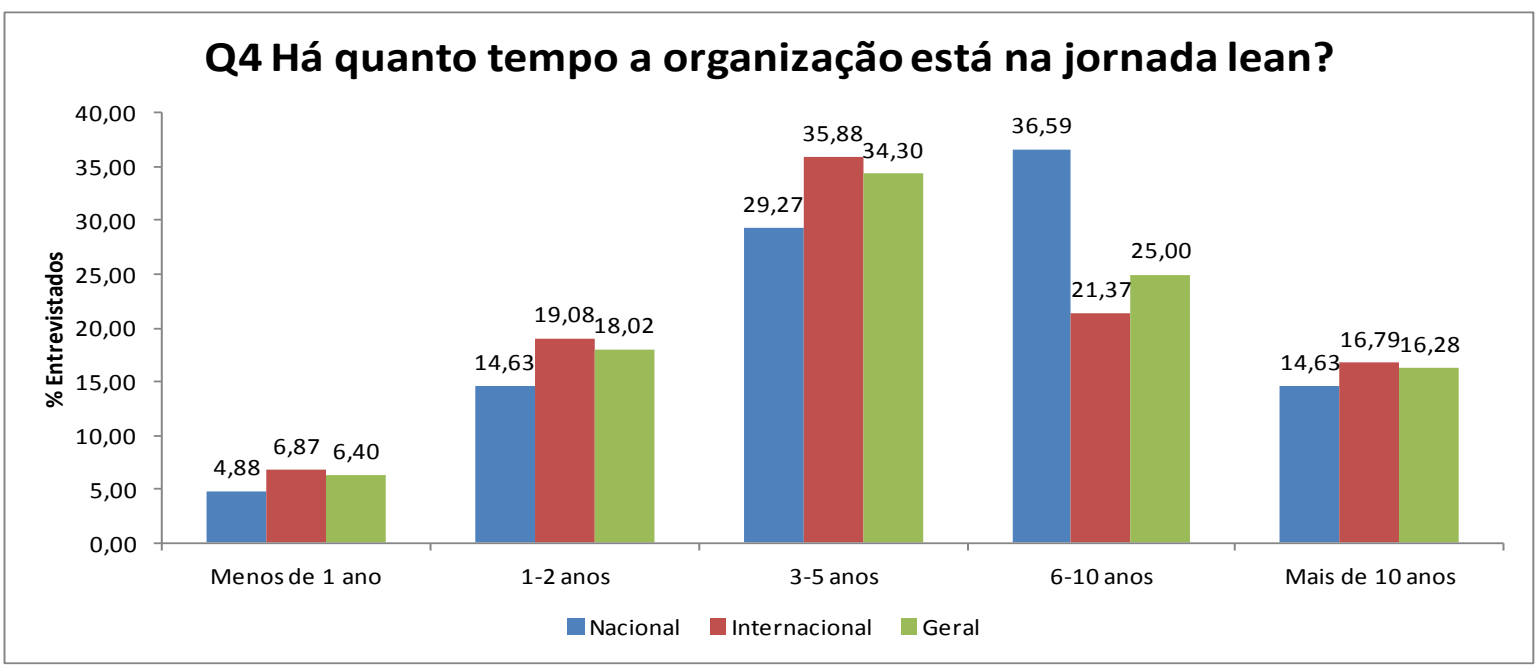

Fonte: Elaborado pela autora

Quando questionados sobre o status da implementação (Tabela 1), apenas 1 entrevistado considera sua empresa completamente lean. Cerca de $29,65 \%$ dos entrevistados aponta sucesso principalmente no chão de fábrica com alguns projetos nas demais áreas da organização.

\begin{tabular}{|c|c|c|c|c|c|c|}
\hline \multirow{2}{*}{ Status da implementação } & \multicolumn{2}{|c|}{ Nacional } & \multicolumn{2}{|c|}{ Internacional } & \multicolumn{2}{|c|}{ Geral } \\
\hline & N. Entrev & \% Entrev & N. Entrev & $\%$ Entrev & N. Entrev & $\%$ Entrev \\
\hline Nenhum pouco lean & & & 1 & 0,76 & 1 & 0,58 \\
\hline $\begin{array}{l}\text { Início da transformação - conversas } \\
\text { e planos iniciais }\end{array}$ & 2 & 4,88 & 10 & 7,63 & 12 & 6,98 \\
\hline Sucesso em algumas áreas pilotos & 9 & 21,95 & 27 & 20,61 & 36 & 20,93 \\
\hline Sucesso parcial & 9 & 21,95 & 29 & 22,14 & 38 & 22,09 \\
\hline $\begin{array}{l}\text { Sucesso principalmente no chão de } \\
\text { fábrica com alguns projetos nas } \\
\text { demais áreas }\end{array}$ & 14 & 34,15 & 37 & 28,24 & 51 & 29,65 \\
\hline $\begin{array}{l}\text { Sucesso na maioria das áreas da } \\
\text { organização }\end{array}$ & 7 & 17,07 & 26 & 19,85 & 33 & 19,19 \\
\hline $\begin{array}{l}\text { Completamente lean e em constante } \\
\text { busca da perfeição }\end{array}$ & & & 1 & 0,76 & 1 & 0,58 \\
\hline Total & 41 & 100,00 & 131 & 100,00 & 172 & 100,00 \\
\hline
\end{tabular}

Tabela 1 - Percepção do status da implementação do lean na organização

Fonte: Elaborado pela autora 
As áreas onde foram realizados mais projetos de melhorias (Tabela 2), entre os respondentes internacionais são Marketing (76,15\%), P\&D (45,38\%) e Laboratórios $(39,23 \%)$; e entre os brasileiros, a Produção $(95,12 \%)$, Logística Interna $(60,98 \%)$ e P\&D $(53,66 \%)$.

\begin{tabular}{|c|c|c|c|c|c|c|}
\hline \multirow{2}{*}{ Área } & \multicolumn{2}{|c|}{ Nacional } & \multicolumn{2}{|c|}{ Internacional } & \multicolumn{2}{|c|}{ Geral } \\
\hline & N. Citaçöes ${ }^{*}$ & $\%$ Respondentes $^{* *}$ & N. Citaçōes* & $\%$ Respondentes $^{* *}$ & N. Citaçōes* ${ }^{*}$ & \% Respondentes ${ }^{* *}$ \\
\hline Marketing & 6 & $14,63 \%$ & 99 & $76,15 \%$ & 105 & $61,40 \%$ \\
\hline Projeto e desenvolvimento & 22 & $53,66 \%$ & 59 & $45,38 \%$ & 81 & $47,37 \%$ \\
\hline Produção - chão de fábrica & 39 & $95,12 \%$ & 37 & $28,46 \%$ & 76 & $44,44 \%$ \\
\hline Laboratório & 9 & $21,95 \%$ & 51 & $39,23 \%$ & 60 & $35,09 \%$ \\
\hline $\mathrm{RH}$ & 11 & $26,83 \%$ & 48 & $36,92 \%$ & 59 & $34,50 \%$ \\
\hline Financeiro & 13 & $31,71 \%$ & 43 & $33,08 \%$ & 56 & $32,75 \%$ \\
\hline Logística externa / distribuição & 9 & $21,95 \%$ & 46 & $35,38 \%$ & 55 & $32,16 \%$ \\
\hline Controladoria fiscal & 9 & $21,95 \%$ & 40 & $30,77 \%$ & 49 & $28,65 \%$ \\
\hline Comercial & 13 & $31,71 \%$ & 34 & $26,15 \%$ & 47 & $27,49 \%$ \\
\hline Compras & 14 & $34,15 \%$ & 25 & $19,23 \%$ & 39 & $22,81 \%$ \\
\hline Logística interna & 25 & $60,98 \%$ & 12 & $9,23 \%$ & 37 & $21,64 \%$ \\
\hline Qualidade & 21 & $51,22 \%$ & 12 & $9,23 \%$ & 33 & $19,30 \%$ \\
\hline Almoxarifado & 20 & $48,78 \%$ & 10 & $7,69 \%$ & 30 & $17,54 \%$ \\
\hline Gestão & 13 & $31,71 \%$ & 12 & $9,23 \%$ & 25 & $14,62 \%$ \\
\hline Assistência técnica / pós venda & 11 & $26,83 \%$ & 5 & $3,85 \%$ & 16 & $9,36 \%$ \\
\hline Total de citações & 235 & & 533 & & 768 & \\
\hline
\end{tabular}

Tabela 2 - Áreas onde foram realizados projetos de melhoria

Fonte: Elaborado pela autora

\section{3 Fatores chave de sucesso}

$\mathrm{Na}$ seção Cultura Organizacional (Tabela 3) as questões em que houve menor concordância com a afirmação são referentes ao reconhecimento dos funcionários pelas sugestões dadas, $(42,69 \%)$ e, ao alinhamento dos objetivos estratégicos com o lean $(41,18 \%)$. Entre os respondentes internacionais, estes mesmos pontos aparecem com 48,46\% e $43,41 \%$ respectivamente, e ainda pode-se incluir a questão sobre motivar as pessoas a identificar e eliminar desperdícios $(42,75 \%)$. No âmbito nacional, os itens de maior discordância têm relação com o alinhamento dos objetivos estratégicos $(34,15 \%)$ e a alta gestão entender e se i 


\begin{tabular}{l|c|c|c|c|c|c}
\hline \multicolumn{1}{c|}{ Questões } & \multicolumn{2}{c|}{ Nacional } & \multicolumn{2}{c|}{ Internacional } & \multicolumn{2}{c}{ Geral } \\
\cline { 2 - 7 } & C+CT & N+D+DT & C+CT & N+D+DT & C+CT & N+D+DT \\
\hline $\begin{array}{l}\text { Os funcionários são reconhecidos pelas } \\
\text { sugestões dadas }\end{array}$ & 75,61 & 24,39 & 51,54 & $\mathbf{4 8 , 4 6}$ & 57,31 & $\mathbf{4 2 , 6 9}$ \\
$\begin{array}{l}\text { Os objetivos estratégicos estão alinhados } \\
\text { Com a cultura lean }\end{array}$ & 65,85 & $\mathbf{3 4 , 1 5}$ & 56,59 & $\mathbf{4 3 , 4 1}$ & 58,82 & $\mathbf{4 1 , 1 8}$ \\
$\begin{array}{l}\text { As pessoas são motivadas a identificar e } \\
\text { eliminar desperdícios }\end{array}$ & 73,17 & 26,83 & 57,25 & 42,75 & 61,05 & 38,95 \\
$\begin{array}{l}\text { A alta gestão entende e se importa com } \\
\text { o lean }\end{array}$ & 68,29 & $\mathbf{3 1 , 7 1}$ & 63,36 & 36,64 & 64,53 & 35,47 \\
$\begin{array}{l}\text { Os projetos de melhoria são levados } \\
\text { adiante }\end{array}$ & 90,24 & 9,76 & 69,47 & 30,53 & 74,42 & 25,58 \\
$\begin{array}{l}\text { As ideias/sugestões dadas são } \\
\text { valorizadas pela organização }\end{array}$ & 82,93 & 17,07 & 73,08 & 26,92 & 75,44 & 24,56 \\
$\begin{array}{l}\text { A empresa possui um programa de } \\
\text { ideias/sugestões para projetos de } \\
\text { melhoria }\end{array}$ & 85,37 & 14,63 & 80,92 & 19,08 & 81,98 & 18,02 \\
\hline
\end{tabular}

\section{CT: Concordo Totalmente, C: Concordo; N: Neutro; D: Discordo; DT: Discordo Totalmente}

\section{Tabela 3 - Resumo da seção Cultura Organizacional}

Fonte: Elaborado pela autora

A análise dos dados da seção Liderança (Tabela 4) demonstra uma diferença na percepção dos entrevistados quando comparamos as três áreas. A maioria dos entrevistados $(65,29 \%)$ concorda que os líderes do chão de fábrica são agentes de mudança da transformação lean. De modo geral, apenas 36,63\% e 37,43\%, acreditam que os líderes das áreas de Suporte e Apoio, respectivamente, são agentes de transformação.

Ainda, nota-se que os resultados envolvendo a liderança do Chão de Fábrica foram melhores em todas as questões quando comparadas às áreas de Suporte e Apoio. Para o Chão de Fábrica, o maior problema na opinião dos entrevistados $(38,24 \%)$, é atender o fluxo de valor trabalhando em conjunto com as demais áreas. Outro ponto a considerar, é que no resultado geral nenhuma das afirmações relacionadas às áreas de Apoio e Suporte teve um percentual de concordância maior que $50 \%$. 


\begin{tabular}{|c|c|c|c|c|c|c|}
\hline \multirow{2}{*}{ Questões } & \multicolumn{2}{|c|}{ Nacional } & \multicolumn{2}{|c|}{ Internacional } & \multicolumn{2}{|c|}{ Geral } \\
\hline & $\mathrm{C}+\mathrm{CT}$ & $\mathrm{N}+\mathrm{D}+\mathrm{DT}$ & $\mathrm{C}+\mathrm{CT}$ & $\mathrm{N}+\mathrm{D}+\mathrm{DT}$ & $\mathrm{C}+\mathrm{CT}$ & $\mathrm{N}+\mathrm{D}+\mathrm{DT}$ \\
\hline $\begin{array}{l}\text { Os líderes dessas áreas são agentes de mudança da } \\
\text { tr ansformação lean. (A suporte) }\end{array}$ & 19,51 & 80,49 & 41,98 & 58,02 & 36,63 & 63,37 \\
\hline $\begin{array}{l}\text { Os líderes dessas áreas são agentes de mudança da } \\
\text { tr ansformação lean. (A apoio) }\end{array}$ & 37,50 & 62,50 & 37,40 & 62,60 & 37,43 & 62,57 \\
\hline $\begin{array}{l}\text { Os líderes dessas áreas buscam atender of fluxo de } \\
\text { valor trabalhando em conjunto com os demais } \\
\text { departamentos e funçốes. (A. apoio) }\end{array}$ & 46,34 & 53,66 & 35,38 & 64,62 & 38,01 & 61,99 \\
\hline $\begin{array}{l}\text { Os líderes dessas áreas entendem o conceito de } \\
\text { fluxo de valor. (A. suporte) }\end{array}$ & 39,02 & 60,98 & 44,53 & 55,47 & 43,20 & 56,80 \\
\hline $\begin{array}{l}\text { Os líderes dessas áreas buscam atender of fluxo de } \\
\text { valor trabalhando em conjunto com os demais } \\
\text { departamentos e funçốes. (A. suporte) }\end{array}$ & 41,46 & 58,54 & 44,19 & 55,81 & 43,53 & 56,47 \\
\hline $\begin{array}{l}\text { Os líderes dessas áreas entendem o } \\
\text { fluxo de valor. (A. apoio) }\end{array}$ & 53,66 & 46,34 & 43,51 & 56,49 & 45,93 & 54,07 \\
\hline $\begin{array}{l}\text { Os líderes dessas áreas conhecem e se importam } \\
\text { com o lean. (A suporte) }\end{array}$ & 51,22 & 48,78 & 48,46 & 51,54 & 49,12 & 50,88 \\
\hline $\begin{array}{l}\text { Os líderes dessas áreas conhecem e se importam } \\
\text { com o lean. (A apoio) }\end{array}$ & 58,54 & 41,46 & 46,92 & 53,08 & 49,71 & 50,29 \\
\hline $\begin{array}{l}\text { A comunicação dos líderes com seus subordinados é } \\
\text { ef etiva e clara }\end{array}$ & 63,41 & 36,59 & 46,51 & 53,49 & 50,59 & 49,41 \\
\hline $\begin{array}{l}\text { Os líderes visitam frequentemente o local de trabalho } \\
\text { (gemba) }\end{array}$ & 65,85 & 34,15 & 49,61 & 50,39 & 53,53 & 46,47 \\
\hline $\begin{array}{l}\text { Os líderes dessas áreas buscam atender o fluxo de } \\
\text { valor trabalhando em conjunto com os demais } \\
\text { departamentos e funçốes. (Chão de fábrica) }\end{array}$ & 68,29 & 31,71 & 59,69 & 40,31 & 61,76 & 38,24 \\
\hline $\begin{array}{l}\text { Os líderes da organização criam um forte senso de } \\
\text { propósito ou missão }\end{array}$ & 60,98 & 39,02 & 65,38 & 34,62 & 64,33 & 35,67 \\
\hline $\begin{array}{l}\text { Os líderes dessas áreas são agentes de mudança da } \\
\text { transformação lean. (Chão de fábrica) }\end{array}$ & 75,61 & 24,39 & 62,02 & 37,98 & 65,29 & 34,71 \\
\hline $\begin{array}{l}\text { Os líderes dessas áreas entendem o conceito de } \\
\text { fluxo de valor. (Chão de fábrica) }\end{array}$ & 75,61 & 24,39 & 64,62 & 35,38 & 67,25 & 32,75 \\
\hline $\begin{array}{l}\text { Os líderes dessas áreas conhecem e se importam } \\
\text { com o lean. (Chão de fábrica) }\end{array}$ & 87,80 & 12,20 & 68,99 & 31,01 & 73,53 & 26,47 \\
\hline
\end{tabular}

CT: Concordo Totalmente, C: Concordo; N: Neutro; D: Discordo; DT: Discordo Totalmente

Tabela 4 - Resumo da seção Liderança

Fonte: Elaborado pela autora.

Na seção Abordagem (Tabela 5), o ponto onde o maior número de entrevistados não concorda com a afirmação foi na questão do uso do MFV para enxergar desperdícios nos processos administrativos. Mais de 50\% dos entrevistados não concorda que as áreas de Apoio e Suporte trabalham em conjunto com as demais para eliminar desperdícios e alcançar melhorias no fluxo. Além disso, mais uma vez, percebe-se que os pontos de maior concordância dos entrevistados estão relacionados ao Chão de Fábrica. 


\begin{tabular}{|c|c|c|c|c|c|c|}
\hline \multirow{2}{*}{ Questões } & \multicolumn{2}{|c|}{ Nacional } & \multicolumn{2}{|c|}{$\underset{\text { I I }}{\text { Internaciona }}$} & \multicolumn{2}{|c|}{ Geral } \\
\hline & $\mathrm{C}+\mathrm{CT}$ & $\frac{T}{N+D+D}$ & $\mathrm{C}+\mathrm{CT}$ & $\frac{T}{N+D+D}$ & $\mathrm{C}+\mathrm{CT}$ & 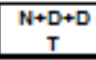 \\
\hline $\begin{array}{l}\text { O mapeamento do fluxo de valor é usado para enxergar os } \\
\text { desperdícios dos processos administrativos }\end{array}$ & 47,5 & 52,5 & 43,51 & 56,49 & 44,44 & 55,56 \\
\hline $\begin{array}{l}\text { Essa área trabalha em conjunto com as demais áreas, } \\
\text { conforme as interações do processo, para eliminar } \\
\text { desperdícios e identificar melhorias no fluxo. (A. Suporte) }\end{array}$ & 37,5 & 62,5 & 51,15 & 48,85 & 47,95 & 52,05 \\
\hline $\begin{array}{l}\text { Essa área trabalha em conjunto com as demais áreas, } \\
\text { conforme as interações do processo, para eliminar } \\
\text { desperdícios e identificar melhorias no fluxo. (A. Apoio) }\end{array}$ & 55 & 45 & 48,09 & 51,91 & 49,71 & 50,29 \\
\hline $\begin{array}{l}\text { Os problemas identificados nessas áreas são tratados } \\
\text { utilizando uma metodologia de análise e solução de } \\
\text { problemas com tratativa da causa raiz. (A. Apoio) }\end{array}$ & 52,5 & 47,5 & 49,61 & 50,39 & 50,3 & 49,7 \\
\hline $\begin{array}{l}\text { Essas áreas possuem indicadores com metas definidas e } \\
\text { que buscam a melhoria contínua. (A. Apoio) }\end{array}$ & 65 & 35 & 48,85 & 51,15 & 52,63 & 47,37 \\
\hline $\begin{array}{l}\text { Os problemas identificados nessas áreas são tratados } \\
\text { utilizando uma metodologia de análise e solução de } \\
\text { problemas com tratativa da causa raiz. (A. Suporte) }\end{array}$ & 47,5 & 52,5 & 54,26 & 45,74 & 52,66 & 47,34 \\
\hline $\begin{array}{l}\text { Essas áreas possuem indicadores com metas definidas e } \\
\text { que buscam a melhoria contínua. (A. Suporte) }\end{array}$ & 57,5 & 42,5 & 52,67 & 47,33 & 53,8 & 46,2 \\
\hline $\begin{array}{l}\text { De modo geral, a organização utiliza o mapeamento do } \\
\text { fluxo de valor para enxergar os desper dícios }\end{array}$ & 65 & 35 & 53,44 & 46,56 & 56,14 & 43,86 \\
\hline $\begin{array}{l}\text { Essa área trabalha em conjunto com as demais ár eas, } \\
\text { conforme as interações do processo, para eliminar } \\
\text { desperdícios e identificar melhorias no fluxo. (Chão de } \\
\text { fábrica) }\end{array}$ & 80 & 20 & 66,92 & 33,08 & 70 & 30 \\
\hline $\begin{array}{l}\text { Os problemas identificados nessas áreas são tratados } \\
\text { utilizando uma metodologia de análise e solução de } \\
\text { problemas com tratativa da causa raiz. (Chão de fábrica) }\end{array}$ & 85 & 15 & 73,44 & 26,56 & 76,19 & 23,81 \\
\hline São definidas metas claras e mensuráv eis para cada projeto & 87,5 & 12,5 & 76,34 & 23,66 & 78,95 & 21,05 \\
\hline $\begin{array}{l}\text { Essas áreas possuem indicadores com metas definidas e } \\
\text { que buscam a melhoria contínua. (Chão de fábrica) }\end{array}$ & 90 & 10 & 78,46 & 21,54 & 81,18 & 18,82 \\
\hline $\begin{array}{l}\text { Os projetos de melhoria seguem uma metodologia definida } \\
\text { para implementação }\end{array}$ & 92,5 & 7,5 & 80,92 & 19,08 & 83,63 & 16,37 \\
\hline
\end{tabular}

CT: Concordo Totalmente, C: Concordo; N: Neutro; D: Discordo; DT: Discordo Totalmente

Tabela 5 - Resumo da seção Abordagem

Fonte: Elaborado pela autora.

$\mathrm{Na}$ seção Treinamento e Conhecimento, as questões nas quais houve menor concordância estão ligadas as pessoas das áreas de Suporte e Apoio. A maioria dos entrevistados acredita que as pessoas dessas áreas não conhecem os sete desperdícios e as ferramentas para eliminá-los. 


\begin{tabular}{|c|c|c|c|c|c|c|}
\hline \multirow{2}{*}{ Questões } & \multicolumn{2}{|c|}{ Nacional } & \multicolumn{2}{|c|}{$\underset{\text { I }}{\text { Internaciona }}$} & \multicolumn{2}{|c|}{ Geral } \\
\hline & $\mathrm{C} * \mathrm{Cr}$ & 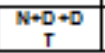 & C*ct & 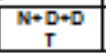 & $\mathrm{C} * \mathrm{CT}$ & $\underset{T}{N+D+D}$ \\
\hline $\begin{array}{l}\text { As pessoas dessa área conhecem e com batem os sete } \\
\text { desperdicios. (A. Suporte) }\end{array}$ & 30,77 & 69,23 & 46,51 & 53,49 & 42,86 & 57,14 \\
\hline $\begin{array}{l}\text { Pessoas dessas áreas conhecem e utilizam as ferram entas } \\
\text { do lean para eliminar desperdicios. (A Suporte) }\end{array}$ & 42,11 & 57,89 & 46,51 & 53,49 & 45,51 & 54,49 \\
\hline $\begin{array}{l}\text { As pessoas dessa área conhecem e combatem os sete } \\
\text { desperdicios. (A Apoio) }\end{array}$ & 61,54 & 38,46 & 44,53 & 55,47 & 48,50 & 51,50 \\
\hline $\begin{array}{l}\text { Pessoas dessas áreas conhecem e utilizam as ferram entas } \\
\text { do lean para eliminar desperdicios. (A Apoio) }\end{array}$ & 74,36 & 25,64 & 47,29 & 52,71 & 53,57 & 46,43 \\
\hline $\begin{array}{l}\text { As pessoas dessa área conhecem e usam a metodologia da } \\
\text { organiza ção para análise e solu çâo de problem as. (A } \\
\text { Apoio) }\end{array}$ & 62,50 & 37,50 & 51,15 & 48,85 & 53,80 & 46,20 \\
\hline $\begin{array}{l}\text { As pessoas dessa área conh ecem e usam a m etodologia da } \\
\text { organiza ção para análise e solu ção de problemas. (A } \\
\text { Suporte) }\end{array}$ & 50,00 & 50,00 & 55,73 & 44,27 & 54,39 & 45,61 \\
\hline Essa área utiliza funcionários polivantes (A Suporte) & 60,53 & 39,47 & 53,08 & 46,92 & 54,76 & 45,24 \\
\hline Essa área utiliza funcionários polivantes (A Apoio) & 66,67 & 33,33 & 54,20 & 45,80 & 57,06 & 42,94 \\
\hline $\begin{array}{l}\text { Pessoas dessas áreas são envolvidas em kaizens/projetos } \\
\text { de m elhoria realizados na orga niza ção. (A Suporte) }\end{array}$ & 69,23 & 30,77 & 62,02 & 37,98 & 63,69 & 36,31 \\
\hline $\begin{array}{l}\text { Pessoas dessas áreas são envolvidas em kaizens/projetos } \\
\text { de melhoria realizados na organiza ção. (A Apoio) }\end{array}$ & 87,18 & 12,82 & 59,69 & 40,31 & 66,07 & 33,93 \\
\hline $\begin{array}{l}\text { As pessoas dessa área receberam treinam ento sobre os } \\
\text { principios do lean no último ano. (A Apoio) }\end{array}$ & 65,00 & 35,00 & 66,41 & 33,59 & 66,08 & 33,92 \\
\hline $\begin{array}{l}\text { As pessoas dessa área receberam treinamento sobre os } \\
\text { principios do lean no último ano. (A Suporte) }\end{array}$ & 56,41 & 43,59 & 69,47 & 30,53 & 66,47 & 33,53 \\
\hline $\begin{array}{l}\text { As pessoas dessa área conhecem e usam a metodologia da } \\
\text { organiza ção para análise e solu ção de problemas. (Chão } \\
\text { de fábrica) }\end{array}$ & 77,50 & 22,50 & 66,15 & 33,85 & 68,82 & 31,18 \\
\hline $\begin{array}{l}\text { As pessoas dessa área conhecem e combatem os sete } \\
\text { desperdícios. (Chão de fábrica) }\end{array}$ & 79,49 & 20.51 & 66,67 & 33,33 & 69,64 & 30,36 \\
\hline $\begin{array}{l}\text { Pessoas dessas áreas conhecem e utilizam as ferram entas } \\
\text { do lean para eliminar desperdícios. (Chão de fábrica) }\end{array}$ & 84,62 & 15,38 & 67.19 & 32,81 & 71,26 & 28,74 \\
\hline Essa área utiliza funcionários polivantes (Chão de fábrica) & 82,05 & 17,95 & 72,31 & 27,69 & 74,56 & 25,44 \\
\hline $\begin{array}{l}\text { As pessoas dessa área receberam treinam ento sobre os } \\
\text { princípios do lean no último a no. (Chäo de fábrica) }\end{array}$ & 82,50 & 17,50 & 77,69 & 22,31 & 78,82 & 21,18 \\
\hline $\begin{array}{l}\text { Pessoas dessas áreas são envolvidas em kaizens/projetos } \\
\text { de melhoria realizados na orga niza ção. (Chão de fábrica) }\end{array}$ & 92,31 & 7,69 & 79,69 & 20,31 & 82,63 & 17,37 \\
\hline
\end{tabular}

\section{CT: Concordo Totalmente, C: Concordo; N: Neutro; D: Discordo; DT: Discordo Totalmente}

\section{Tabela 6 - Resumo da seção Treinamento e Conhecimento}

Fonte: Elaborado pela autora.

Na seção Pessoas (Tabela 7) novamente, percebe-se a diferença entre o resultado do Chão de Fábrica e das áreas de Suporte e Apoio. O ponto mais frágil na opinião da maioria dos entrevistados refere-se às pessoas das áreas de Suporte $(60,71 \%)$ e Apoio $(52,66 \%)$ não acreditarem que as ferramentas do lean são aplicáveis as suas atividades.

Note-se que as questões referentes à resistência a mudança tem conotação negativa, assim não podem ser comparadas as demais, sendo apresentadas em separado e classificadas pelo percentual alcançado com respostas "concordo" e "concordo totalmente". Mesmo nesse ponto, os entrevistados consideram que as pessoas do Chão de Fábrica são menos resistentes á mudança comparadas às áreas de Apoio e Suporte. 


\begin{tabular}{|c|c|c|c|c|c|c|}
\hline \multirow{2}{*}{ Questões } & \multicolumn{2}{|c|}{ Nacional } & \multicolumn{2}{|c|}{ Internacional } & \multicolumn{2}{|c|}{ G eral } \\
\hline & $\mathrm{C}+\mathrm{CT}$ & $\mathrm{N}+\mathrm{D}+\mathrm{DT}$ & $\mathrm{C}+\mathrm{CT}$ & $\mathrm{N}+\mathrm{D}+\mathrm{DT}$ & $\mathrm{C}+\mathrm{CT}$ & $N+D+D T$ \\
\hline $\begin{array}{l}\text { As pessoas dessas áreas acreditam que as } \\
\text { ferrament as do lean são aplicáveis ao seu trabalho. } \\
\text { (A. Suporte) } \\
\text { As pessoas dessas áreas acredit am que as }\end{array}$ & 40,00 & 60,00 & 39,06 & 60.94 & 39,29 & 60,71 \\
\hline $\begin{array}{l}\text { As pessoas dessas areas acreditam que as } \\
\text { ferrament as do lean são aplicáveis ao seu trabalho. } \\
\text { (A. Apoio) }\end{array}$ & 65,00 & 35,00 & 41,86 & 58,14 & 47,34 & 52,66 \\
\hline $\begin{array}{l}\text { As pessoas dessas áreas frequentemente se } \\
\text { ervolvem em projetos de melhoria. (A. Suporte) }\end{array}$ & 48,72 & 51,28 & 51,54 & 48,46 & 50,89 & 49.11 \\
\hline $\begin{array}{l}\text { A empresa reconhece quem está comprometido com } \\
\text { a melhoria contínua }\end{array}$ & 69,23 & 30,77 & 50,00 & 50.00 & 54,44 & 45,56 \\
\hline $\begin{array}{l}\text { As pessoas dessas áreas frequentemente se } \\
\text { ervolvem em projet os de melhoria. (A. Apoio) }\end{array}$ & 69,23 & 30,77 & 53,08 & 46,92 & 56,80 & 43,20 \\
\hline $\begin{array}{l}\text { A participaccão em projetos de melhoria é um dos } \\
\text { fatores avaliados no desempenho do funcionário }\end{array}$ & 58,97 & 41,03 & 57,69 & 42,31 & 57,99 & 42,01 \\
\hline $\begin{array}{l}\text { As pessoas dessas áreas se preocupam com a } \\
\text { qualidade, custo e prazo relacionado às suas } \\
\text { atividades. (A. Apoio) }\end{array}$ & 76,92 & 23,08 & 58,14 & 41,86 & 62,50 & 37,50 \\
\hline $\begin{array}{l}\text { As pessoas dessas áreas se preocupam com a } \\
\text { qualidade, custo e prazo relacionado às suas } \\
\text { atividades. (A. Suporte) }\end{array}$ & 71,05 & 28,95 & 62,02 & 37,98 & 64,07 & 35,93 \\
\hline $\begin{array}{l}\text { As pessoas dessas áreas acreditam que as } \\
\text { ferramentas do lean são aplicáveis ao seu trabalho. } \\
\text { (Châo de fábrica) }\end{array}$ & 82,50 & 17,50 & 65,12 & 34,88 & 69,23 & 30,77 \\
\hline $\begin{array}{l}\text { As pessoas dessas ár eas frequentemente se } \\
\text { ervolvem em projetos de melhoria. (Chão de fábrica) }\end{array}$ & 82,05 & 17,95 & 71,32 & 28,68 & 73,81 & 26,19 \\
\hline $\begin{array}{l}\text { As pessoas dessas áreas se preocupam com a } \\
\text { qualidade, custo e prazo relacionado às suas } \\
\text { atividades. (Chão de fábrica) }\end{array}$ & 87,18 & 12,82 & 81,40 & 18,60 & 82,74 & 17,26 \\
\hline \multirow{2}{*}{ Questões* (com conotação neg ativa) } & \multicolumn{2}{|c|}{ Nacional } & \multicolumn{2}{|c|}{ Internacional } & \multicolumn{2}{|c|}{ Geral } \\
\hline & $\mathrm{C}+\mathrm{CT}$ & $\mathrm{N}+\mathrm{D}+\mathrm{DT}$ & $\mathrm{C}+\mathrm{CT}$ & $\mathrm{N}+\mathrm{D}+\mathrm{DT}$ & $\mathrm{C}+\mathrm{CT}$ & $\mathrm{N}+\mathrm{D}+\mathrm{DT}$ \\
\hline $\begin{array}{l}\text { As pessoas dessas áreas são resistentes à mudança. } \\
\text { (A. Suporte) }\end{array}$ & 51,28 & 48,72 & 47,29 & 52,71 & 48,21 & 51,79 \\
\hline $\begin{array}{l}\text { As pessoas dessas áreas são resistentes à mudança. } \\
\text { (A. Apoio) }\end{array}$ & 41,03 & 58,97 & 46,51 & 53,49 & 45,24 & 54,76 \\
\hline $\begin{array}{l}\text { As pessoas dessas áreas são resistentes à mudança. } \\
\text { (Chão de fábrica) }\end{array}$ & 38,46 & 61,54 & 39,84 & 60,16 & 39,52 & 60,48 \\
\hline
\end{tabular}

CT: Concordo Totalmente, C: Concordo; N: Neutro; D: Discordo; DT: Discordo Totalmente

Tabela 7 - Resumo da seção Pessoas

Fonte: Elaborado pela autora.

\subsection{Análise fatores chave}

Em primeiro lugar, chama a atenção o fato de que, embora mais de $75 \%$ dos entrevistados informou estar na jornada lean há mais de três anos, apenas 19,77\% acredita ter sucesso na maioria das áreas ou total.

É notória a diferença entre todos os fatores quando comparamos os resultados entre chão de fábrica e as áreas de apoio e suporte. Para verificar se existe diferença significativa entre as três áreas, foram verificadas as questões que comparam o mesmo critério por meio do teste estatístico não-paramétrico de Friedman, o qual realiza um teste de comparação de grupos relacionados (SIEGEL, 1975, p. 189). Para todas as questões testadas, as respostas referentes ao chão de fábrica são diferentes, a 5\% de significância, das respostas para as áreas de suporte e de apoio.

Para comparar os fatores chave e o seu desenvolvimento dentro de cada área pode-se observar a Figura 4, a qual ilustra os resultados médios de cada fator por área. O fator cultura 
organizacional por ser genérico, não aparece nessa análise. Claramente confirma-se que o chão de fábrica se destaca com resultados positivos em todos os quatro fatores.

Figura 4 - Resultado médio de cada fator x Áreas

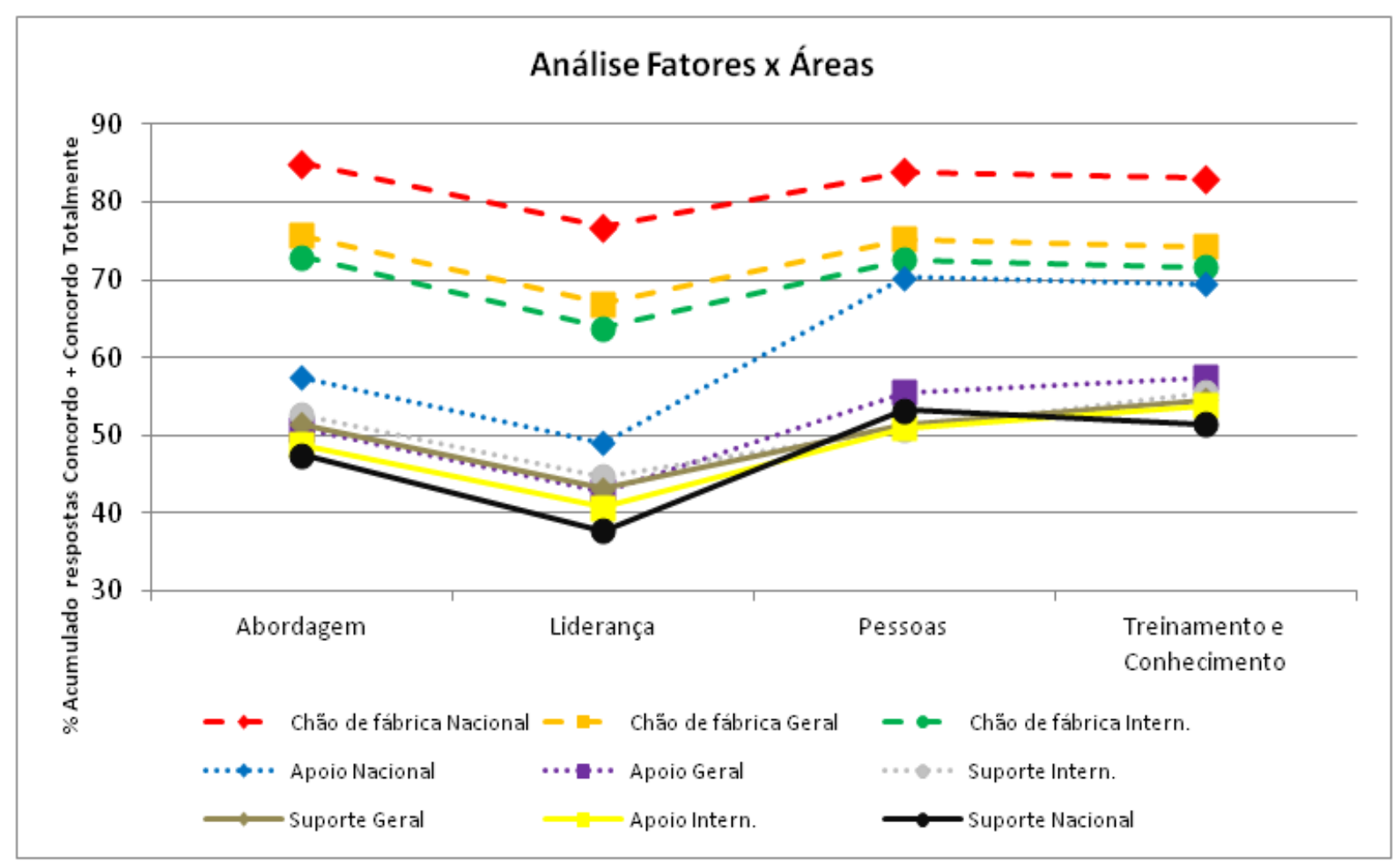

Fonte: Elaborado pela autora

Em síntese, o fator liderança é o ponto fundamental para o sucesso, os líderes precisam ser o exemplo da mudança que se espera. Fica claro que para o sucesso do lean a organização deve estar com seus objetivos estratégicos alinhados promovendo uma cultura lean, dessa forma seus líderes estarão engajados e as pessoas motivadas (GREEF; FREITAS; ROMANEL, 2012; TAPPING; SHUKER, 2010). Nesse contexto, a liderança assume papel fundamental na disseminação da cultura lean.

\section{Conclusão}

O tema deste trabalho é o lean office, que busca traduzir os conceitos lean, tão utilizados na produção, para as áreas e processos administrativos. Como objetivo principal buscou-se identificar as dificuldades de implementação do lean office, através da análise de cinco fatores considerados chave para o sucesso da implementação do lean: cultura organizacional, liderança, abordagem, treinamento e conhecimento e pessoas.

Os itens em que os entrevistados apontam as maiores divergências são relacionados às áreas de apoio e suporte. O primeiro ponto de desacordo está relacionado aos líderes das áreas de apoio e suporte não serem agentes de mudança na transformação lean. Em seguida, os entrevistados acreditam que os líderes das áreas de apoio têm dificuldade em atender o fluxo de valor trabalhando em conjunto com os demais departamentos e funções. Ainda, podem-se destacar como ponto fraco das áreas de suporte, as pessoas dessas áreas não identificam aplicação das ferramentas lean em suas atividades e com isso não combatem os sete desperdícios.

É interessante destacar, que existiram algumas diferenças relevantes entre os resultados dos entrevistados nacionais e internacionais como, por exemplo, o interesse dos 
respondentes internacionais na área de marketing, enquanto entre os brasileiros é a área de menor representatividade. Além disso, os resultados nacionais foram mais positivos quando comparados aos internacionais, com exceção da área de suporte que teve no âmbito nacional o pior resultado.

A análise dos dados coletados demonstra que por se tratar de uma filosofia de gestão, a organização precisa estar comprometida a adotar uma cultura lean, e não somente utilizar suas técnicas e ferramentas. Assim, a implementação exige uma quebra de paradigma, principalmente gerencial, uma vez que a mudança deve ocorrer de cima para baixo e deve envolver todos os níveis. Este é o primeiro desafio para adotar uma cultura enxuta (LIKER, 2005).

Referências

ANTUNES, Junico. Sistemas de produção - Conceitos e práticas para projeto e gestão da produção enxuta. Porto Alegre: Bookman, 2008.

BABBIE, Earl. Métodos de pesquisa survey. 2a. ed. Belo Horizonte: UFMG, 2003.

CHEN, Joseph C.; COX, Ronald A. Value stream management for lean office - A case study. American Journal of Industrial and Business Management, v. 02, n. 02, p. 17-29, 2012. Disponível em:

http://www.scirp.org/journal/PaperDownload.aspx ?DOI=10.4236/ajibm.2012.22004> .Acesso em: 6 mar. 2013.

FREITAS, André Luís Policani; RODRIGUES, Sidilene Gonçalves. A avaliação da confiabilidade de questionários: uma análise utilizando o coeficiente alfa de Cronbach. Simpep - Simpósio de Engenharia de Produção, v. XII, 2005.

GONÇALVES, José Ernesto Lima. As empresas são grandes coleções de processos. RAE - Revista de Administração de Empresas, p. 6-19, 2000.

GREEF, Ana Carolina; FREITAS, Maria do Carmo Duarte; ROMANEL, Fabiano Barreto. Lean office: Operação, gerenciamento e tecnologias. 1a. ed. São Paulo: Atlas, 2012. p. 223

KEYTE, Beau; LOCHER, Drew. The complete lean enterprise - Value stream mapping for administrative and office process. New York: Productivity Press, 2004. p. 160

LIKER, Jeffrey K. O Modelo Toyota - 14 princípios de gestão do maior fabricante do mundo. Ed. Porto Alegre: Bookman, 2005. p. 316

LOCHER, Drew. Lean office and service simplified - The definitive how-to guide. 1a. ed. Boca Raton: CRC Press - Taylor \& Francis Group, 2011.

MARCHWINSKI, Chet. New survey: Middle managers are biggest obstacle to lean enterprise. Disponível em: <www.lean.org>. Acesso em: 19 maio 2013.

MCMANUS, Hugh L. Product development value stream mapping (PDVSM)

Manual. Cambridge: [s.n.], 2005. Disponível em: 
<http://lean.mit.edu/downloads/doc_download/1090-product-development-valuestream-mapping-manual>.

MIGUEL, Paulo Augusto Cauchick. Metodologia de pesquisa em engenharia de produção e gestão de operações. 1a. ed. Rio de Janeiro: Elsevier, 2010.

OHNO, Taiichi. O Sistema Toyota de Produção - Além da Produção em Larga Escala. Porto Alegre: Bookman, 1997.

OLIVEIRA, Tânia Modesto Veludo De. Amostragem não Probabilística: Adequação de Situações para uso e Limitações de amostras por Conveniência, Julgamento e Quotas. Administração On Line, v. 2, n. 3, 2001. Disponível em: <http://www.fecap.br/adm_online/art23/tania2.htm>.

SAURIN, Tarcisio Abreu; RIBEIRO, José Luis Duarte; MARODIN, Giuliano Almeida. Identificação de oportunidades de pesquisa a partir de um levantamento da implantação da produção enxuta em empresas do Brasil e do exterior. Gestão \& Produção, v. 17, n. 4, p. 829-841, 2010.

SCHERER, Jonatas Ost. Gestão de riscos em projetos de implantação da metodologia lean. 2012. Universidade Federal do Rio Grande do Sul, 2012

SIEGEL, Sidney. Estatística não-paramétrica para as ciências do comportamento. 1a. ed. Rio de Janeiro: Editora McGraw-Hill do Brasil Ltda, 1975.

TAPPING, Don; SHUKER, Tom. Lean office: Gerenciamento do fluxo de valor para áreas administrativas. 1a. ed. São Paulo: Leopardo Editora, 2010.

TENÓRIO, Fernando Guilherme. Tecnologia da informação - Transformando as organizações e o trabalho. Rio de Janeiro: FGV, 2007.

WOMACK, James P.; JONES, Daniel T. A mentalidade enxuta nas empresas: elimine o desperdício e crie riqueza. 1a. ed. Rio de Janeiro: Campus, 1998. p. 427

WOMACK, James P.; JONES, Daniel T.; ROOS, Daniel. A Máquina que Mudou o Mundo. 10a. ed. São Paulo: Editora Campos, 2004. 